\title{
Internships and Undergraduate Research: Impact, Support, and Institution- alization of an NSF S-STEM Program through Partnerships with Industry and Funding from Federal and Local Workforce Agencies
}

\author{
Dr. Lisa Massi, University of Central Florida
}

Dr. Lisa Massi is the Director of Operations Analysis for Accreditation, Assessment, \& Data Administration in the College of Engineering \& Computer Science at the University of Central Florida. She is Co-PI of a NSF-funded S-STEM program and program evaluator for an NSF-funded REU program. Her research interests include cognitive and non-cognitive factors that impact student persistence and career choices in the STEM fields.

\section{Prof. Michael Georgiopoulos, University of Central Florida}

Michael Georgiopoulos received the Diploma in EE from the National Technical University in Athens, his MS degree and Ph.D. degree in EE from the University of Connecticut, Storrs, CT, in 1981, 1983 and 1986, respectively. He is currently a Professor in the Department of EECS at the University of Central Florida in Orlando, FL. From September 2011 to June 2012 he served as the Interim Assistant Vice President of Research at the Office of Research and Commercialization. Since July 2012 he is serving as the Interim Dean of the College of Engineering and Computer Science.

His research interests lie in the areas of Machine Learning and applications with special emphasis on neural network and neuro-evolutionary algorithms, and their applications. He has published more than 60 journal papers and more than 170 conference papers in a variety of conference and journal venues. He has been an Associate Editor of the IEEE Transactions on Neural Networks from 2002 to 2006, and an Associate Editor of the Neural Networks journal from 2006 to 2012. He has served as the Technical Co-Chair of the IJCNN 2011.

\section{Dr. Cynthia Y. Young, University of Central Florida}

Cynthia Young is an Associate Dean and Professor of Mathematics in the UCF College of Sciences. She is the PI of an NSF Funded Step 1B program called COMPASS, a Co-PI of the NSF-funded SSTEM program at UCF entitled the "Young Entrepreneur and Scholar(YES) Scholarship Program" as well as the NSF-funded STEP program entitled "EXCEL:UCF-STEP Pathways to STEM: From Promise to Prominence." Dr. Young's interests are in improving STEM education.

Dr. Cameron M. Ford, University of Central Florida

Cameron M. Ford is the Founding Director of the UCF Center for Entrepreneurship and Innovation and an Associate Professor of Entrepreneurship at the University of Central Florida. His scholarly interests focus on creativity and entrepreneurship by describing how novel ideas evolve, gain legitimacy, and attract resources during the new venture emergence process.

\section{Dr. Patrice Lancey, University of Central Florida}

Dr. Patrice Lancey is the Director of the UCF Office of Operational Excellence and Assessment Support. She holds a B.A. in Psychology from Brooklyn College and an M.A. and Ph.D. in Clinical Psychology from Wayne State University. She joined the University of Central Florida in 2001 where she coordinates the university wide Institutional Effectiveness Assessment process and supports assessment of academic programs and administrative departments. She also designs statistical studies to provide information about student engagement, institutional conditions that enhance student learning outcomes, progression, and retention to provide reports to decision makers to include upper administration, faculty and staff. Dr. Lancey serves as the assessment specialist for NSF S-STEM program entitled, "Young Entrepreneur and Scholar (YES) Scholarship Program." Prior to this, she held positions at The Johns Hopkins School of Public Health, Westat, Inc., University of Alabama, and Palm Beach Community College. She presents papers 
and workshops for faculty and administrators on educational assessment topics at national conferences and acts as a consultant to other universities. Dr. Lancey serves as a reviewer for assessment proposals for the Association for Institutional Research and Southern Association for Institutional Research. She regularly works with faculty to develop research methodology and student learning assessment.

\section{Dr. Divya Bhati, University of Central Florida}

Dr. Divya Bhati (University of Central Florida: assessment specialist) has extensive expertise in assessment of academic and funded research programs. Dr. Bhati coordinates the university wide Institutional Effectiveness Assessment process and support assessment of academic programs and administrative units. Dr. Bhati assisted faculty in the College of Education as they framed and improved degree program student learning outcomes and measures to align to national accreditation standards and state mandates. Dr. Bhati's research interests include assessment of student learning outcomes, teaching and learning, survey design and research methodology, and research related to human performance.

\section{Mrs. Kim A Small, University of Central Florida College of Engineering and Computer Science}

Kim Small is the Director of Academic Support Services for the College of Engineering and Computer Science. She holds a BS in Business Administration and a MA in Educational Leadership. She joined the University of Central Florida in 1995 and has served in various advising roles for the College of Engineering and Computer Science. She is responsible for coordinating the student support services for undergraduate and graduate students. She is also responsible for running the college retention programs. Mrs. Small's interests lie in the areas of retention and transition of freshmen and transfer students. She has been honored with advising awards from UCF and a NACADA Certificate of Merit for Outstanding Advising Program. Mrs. Small serves as the advisor for the NSF S-STEM program entitled, "Young Entrepreneur and Scholar (YES) Scholarship Program.” 


\title{
Internships and Undergraduate Research: Impact, Support, and Institutionalization of an NSF S-STEM Program Through Partnerships with Industry and Funding from Federal and Local Workforce Agencies
}

\begin{abstract}
The Young Entrepreneur and Scholar (YES) program is a partnership between the College of Engineering \& Computer Science, the College of Sciences, and the College of Business Administration at a large, public university. The YES program was established in 2008 with funding from the National Science Foundation Scholarships in Science, Technology, Engineering, and Mathematics (NSF S-STEM) program. The purpose of the YES program is to prepare academically talented STEM students to enter the workforce or graduate school through formal pathways that offer enhanced educational benefits. STEM students with a declared interest in entrepreneurship/internship or undergraduate research experiences were selected to participate in the YES program through a competitive application process. The educational approach of the YES program has shown positive outcomes and benefits for the students. YES students have reported that cognitive, personal, and professional benefits include real-world experiences, gains in self-confidence, development of their professional persona, confirmation or clarification of career or educational goals, and a support network of friends and professionals through the YES learning community. This paper describes the educational approach, key outcomes, and partnership model of the YES program.
\end{abstract}

\section{Introduction}

In an opinion article published online by U.S. News \& World Report, the presidents of two nonpartisan think tanks (Matt James of the Center for the Next Generation in San Francisco and Neera Tanden of the Center for American Progress in Washington, D.C.) wrote that by 2030, China is expected to have 200 million college graduates, and by 2020 India will be graduating four times the number of college graduates as the United States ${ }^{1}$. To put this in perspective in terms of graduates with technical degrees, India produces around 750,000 engineers per year ${ }^{2}$, China over 1.9 million engineers ${ }^{3}$, and the United States close to 140,000 engineers ${ }^{4}$. Regardless of debates around statistical methodologies used to compare the number of engineers produced by these three countries, there can be little doubt that China and India are producing engineers at a more rapid rate than the United States ${ }^{5}$. The recent (2010) report produced by the National Academies, Rising Above the Gathering Storm, Revisited: Rapidly Approaching Category 56, cited multiple statistics that indicate the United States' competitive edge has declined even further since they published their first Rising Above the Gathering Storm report in $2007^{7}$. The solution lies in innovation from scientific and technological advances and a focus on preparation 
of the student (developing talent) to meet STEM (Science, Technology, Engineering, Mathematics) workforce needs in order to be globally competitive.

\section{Background Information on the College of Engineering \& Computer Science}

The University of Central Florida (UCF), a public university (Carnegie Classification RU/VH: Research Universities - very high research activity), is the second largest university in the nation in terms of student enrollment; Fall 2012 enrollment was 60,101. Enrollment in the College of Engineering \& Computer Science (CECS) was 8,041 (6,739 undergraduates and 1,302 graduates), or approximately $13 \%$ of the university’s enrollment. Among the 11 state universities, the University of Central Florida awarded 16\% (751/4,712) of engineering degrees and 21\% (193/927) of computer science/information science degrees in 2009-10 (the most recent data year available) ${ }^{8}$. Approximately $23 \%$ of the population in the state in 2011 was Hispanic/Latino ${ }^{9}$ which is also reflected in the enrollment numbers of this demographic at the university and within the college. In CECS, the undergraduate Hispanic and African American students represent $22 \%$ and $7 \%$ respectively of the total undergraduate enrollment in the college (double the national rate of $10 \%$ for Hispanics, and higher than the national rate of $5 \%$ for African Americans) ${ }^{4}$. CECS ranks $20^{\text {th }}$ in the number of undergraduate engineering and computer science degrees awarded, $8^{\text {th }}$ to Hispanics, $16^{\text {th }}$ to African Americans, and $35^{\text {th }}$ to women among 348 engineering colleges in the United States ${ }^{4}$ CECS has also been ranked as one of the top ten graduate engineering schools for Hispanics by Hispanic Business Magazine for the past eight years; the current ranking is $6^{\text {th }} 10$.

The College of Engineering \& Computer Science does not require students to participate in coop or internship programs or undergraduate research programs. Various co-op or internship experiences available to students are administered through the university's Office of Experiential Learning, the university's Career Services Office, the Information Technology program within CECS, or sponsored programs within a unit in CECS or on campus. Likewise, undergraduate research experiences are administered through various university programs or offices such as RAMP (Research and Mentoring Program), the Burnett Research Scholars, Honors in the Major (offered through the Burnett Honors College), and the Office of Undergraduate Research, or sponsored program within a unit in CECS.

In 2008, the College of Engineering \& Computer Science established the Young Entrepreneur and Scholar (YES) program with funding from the National Science Foundation (NSF) Scholarships in Science, Technology, Engineering, and Mathematics (S-STEM) program. The YES program is a partnership between the College of Engineering \& Computer Science, the College of Sciences, and the College of Business Administration. The purpose of the YES program is to prepare academically talented STEM students to enter the workforce or graduate school through formal pathways that offer enhanced educational benefits. STEM students with a declared interest in entrepreneurship/internship or undergraduate research experiences (co-op experiences are not offered through the YES program), who meet the YES program's eligibility 
requirements, are selected to participate in the YES program through a competitive application process. Students are placed with a faculty mentor (YES Research Path) or industry mentor (YES Entrepreneurship/Internship Path). In the Entrepreneurship Path students are placed with small, incubator companies that are current or graduated clients of the university's incubator program. In the Internship Path students are placed with mid-size or large corporations or organizations. Students are allowed to switch Paths at certain points in the program - if they so choose - as part of their career exploration process. The YES program also offers other benefits to participants which include academic advising with a YES advisor each semester to check progress to graduation; an intimate learning community of scholars (YES Socials and Workshops); a YES Distinguished Speaker Seminar series; an annual YES Symposium to showcase what they have learned from the mentorship experience through a presentation or poster; and the opportunity to network with members of the YES Advisory Board (comprised primarily of industry professionals plus a few faculty) during the YES Symposium.

YES students are given a scholarship of \$5,000 (fall/spring) based on financial need. A few students choose to continue with their mentoring experience during the summer semester; they have primarily been supported with funds received from a secondary sponsor, the local workforce board, Workforce Central Florida. It is important to provide reasonable financial support to the students so that they do not have to work to support themselves as the secondary goal of the YES program is to graduate students at a faster rate. Research studies have identified financial aid as a critical factor that affects the decision to pursue a college degree and success in degree attainment $^{11,12,13}$, particularly for low-income and minority populations ${ }^{11,12 .}$ In addition to rising tuition rates (UCF has one of the lowest tuition rates in the nation), there are two legislative mandates that have contributed to increased out-of-pocket costs for students. In 1997, the state created the Florida Bright Futures Scholarship which provided full (100\% tuition costs and some fees to top students covered) or partial (75\% tuition costs to good students covered) college scholarships to high school students who met the academic standards. However, the growing popularity and costs of running the program eventually forced the legislature to reduce the scholarship in the last few years to the current model, where students receive a flat rate per credit hour, resulting in a substantially reduced scholarship award amount. Second, pursuant to a state statute enacted in Fall 2009, students are subject to an excess hours penalty where they are charged two times the tuition rate for each credit beyond $110 \%$ of the required hours of the baccalaureate degree program completion requirements.

\section{The Educational Approach Used in Creating the YES Program}

There are numerous benefits to college students who participate in experiential learning activities, the most notable of which is development of the professional persona. Schuurman, Pangborn, and McClintic ${ }^{14}$ assessed the impact of engineering undergraduate work experience and found that the greater the work experience for male or female engineering students, the higher the starting salary and potential for a job offer by graduation. Strauss and Terenzini ${ }^{15}$ analyzed data collected from over 4,000 graduating engineering seniors at 39 engineering 
schools and found that both academic and extra- or co-curricular experiences (which included co-ops and internships) made significant contributions to students' design and analytical skills and team skills. Dansberry ${ }^{16}$ examined 1,080 student surveys collected over a period of three years (2008-2011) from NASA interns in their Undergraduate Student Research Program and found that students reported growth in skill areas related to the ABET $a-k$ student outcomes criteria (such as professional and technical communication, conceptual and analytical ability, applying knowledge, professional qualities, teamwork, leadership, technology, work culture, and organization and planning) and attitudinal change toward their current career path (such as determining individual strength and weaknesses, professional self-confidence, academic motivation, understanding the chosen profession, clarifying career plans and options, and achieving career goals). Research studies have shown that having a personal support system is an important aspect of student persistence ${ }^{17,18,19,20}$ as students struggle to balance work, academic, and social life. Massi et al. ${ }^{21}$ found that engineering and computer science native freshmen and transfer students had similar participation rates for experiential learning activities (co-ops and internships) and reported higher instances of developing close personal friendships at the institution during their undergraduate career compared with non-participants. Employers are more likely to hire paid interns (60\% of 2012 college graduates received a job offer) than unpaid interns (37\% received a job offer) or those who did not participate in an internship (36\% received a job offer $)^{22 .}$ The national conversion rate in 2011 for turning interns to full-time hires was $67 \%$, with $39 \%$ of new college hires from employers' own internship programs ${ }^{23}$.

Students participating in undergraduate research experiences (URE) report parallel benefits to those who participate in co-op or internship experiences. Students who participate in UREs are three times more likely to indicate graduate school intentions ${ }^{24}$ and twice as likely to expect a $\mathrm{PhD}^{25}$ compared with non-participants. Massi et al. ${ }^{24}$ found that URE male and female students showed the same level of interest in continuing on to graduate school as did Lopatto ${ }^{26,27}$. Hathaway, Nagda, and Gregerman ${ }^{28}$ found that participation in a URE lead to actual graduate or professional educational enrollment, which was more significant for URE participants than nonparticipants. Massi et al. ${ }^{24}$ found that $41 \%$ of gains experienced by engineering and computer science URE students were in "clarification or confirmation of career/education paths" compared with $20 \%$ of gains reported by Seymour et al. ${ }^{29}$. However, this difference is probably attributable to the timing of the studies - Massi et al. ${ }^{24}$ surveyed graduating seniors whereas Seymour et al. ${ }^{29}$ interviewed rising seniors. As students approach graduation time, their thoughts are turned more towards deciding on a career. Fifty-one percent of gains were noted in the personal/professional domain (which includes "thinking and working like a scientist") ${ }^{24,29}$. Hunter et al. ${ }^{30}$ found that $57 \%$ of students attributed "gains in confidence" to their "feeling like a scientist."

The advantage of offering undergraduate research and entrepreneurship/ internship experiences through one program is that it creates a cohesive, structured learning community for students to explore career pathways and develop their professional identity. YES student cohorts are 
exposed to the benefits that each experience offers through the YES Distinguished Speaker Series (speakers include an entrepreneur and a researcher), the YES Symposium, and interacting with each other. For example, a Research Path student may be interested in how to commercialize a research project or create a start-up company; or an Entrepreneurship/Internship Path student may be interested in starting a business but realizes that pursuing a graduate degree will provide specialization in the field. A similar educational approach (joining co-op with undergraduate research experiences) with engineering students at the University of Puerto Rico at Mayagüez (UPRM) has shown positive outcomes and benefits for their students ${ }^{31}$. The primary differences between the educational approach of UPRM and the YES program are: a) UPRM's program combines co-op and undergraduate research experiences where YES combines internship and undergraduate research experiences; and b) UPRM's program offers a structured progression of undergraduate research - co-op - undergraduate research whereas YES offers a choice of pathways for internship or undergraduate research, and the flexibility of switching between pathways.

\section{Key Outcomes of the YES Program}

A YES student cohort is recruited at the beginning of the Fall semester each year. Applicants who meet the eligibility requirements of the YES program are selected based on a competitive application process. The eligibility requirements are:

- Declared interest in undergraduate research or entrepreneurship/internship experiences

- Junior or senior enrolled in a STEM major

- U.S. citizen, alien lawfully admitted to the U.S. for permanent residence; national of the U.S. as defined in section 101(a) of the Immigration and Nationality Act; or alien admitted as refugees under section 207 of the Immigration and Nationality Act

- Cumulative GPA of at least 3.0

- Full-time enrollment

- Financial need

- At least two semesters (Fall/Spring) left before graduation

YES Recruitment. The YES program represents a diverse student body. Since the inception of the YES program in 2008, 49 STEM students have participated in the YES program (41\% females, 33\% Hispanic, 8\% Asian, 14\% African American, 2\% Multiracial, 43\% White, 51\% first generation to pursue a bachelor's degree). Fifty-three percent (26/49) were engineering and computer science majors, and 47\% (23/49) represented other STEM majors (Physics, Chemistry, Biology, Biotechnology, Biomedical Sciences, Molecular \& Microbiology, and Forensic Science). Eighty-four percent (41/49) chose the Research Path, 8\% (4/49) the Entrepreneurship/ Internship Path , and 8\% (4/49) were "switchers," that is, they participated in both the Research and Entrepreneurship/ Internship Path. It should be noted that several of the Research Path students (24\% or 10/41) also reported having participated in co-op and internship experiences outside of the YES program. Forty-three STEM faculty have participated as mentors for the 
Research Path students and eight companies have provided industry mentors for the Entrepreneurship/Internship Path students. The YES partnership model and student outcomes are described in Figure 1. In this section, the impact on student success is described below for each of the outcomes listed in Figure 1. For persistence to graduation, we look at three aspects: 1) actual graduation rates, 2) actual time to degree for those who have graduated, and 3) a predictive model for progress to graduation. In the following section, the YES partnership model is described.

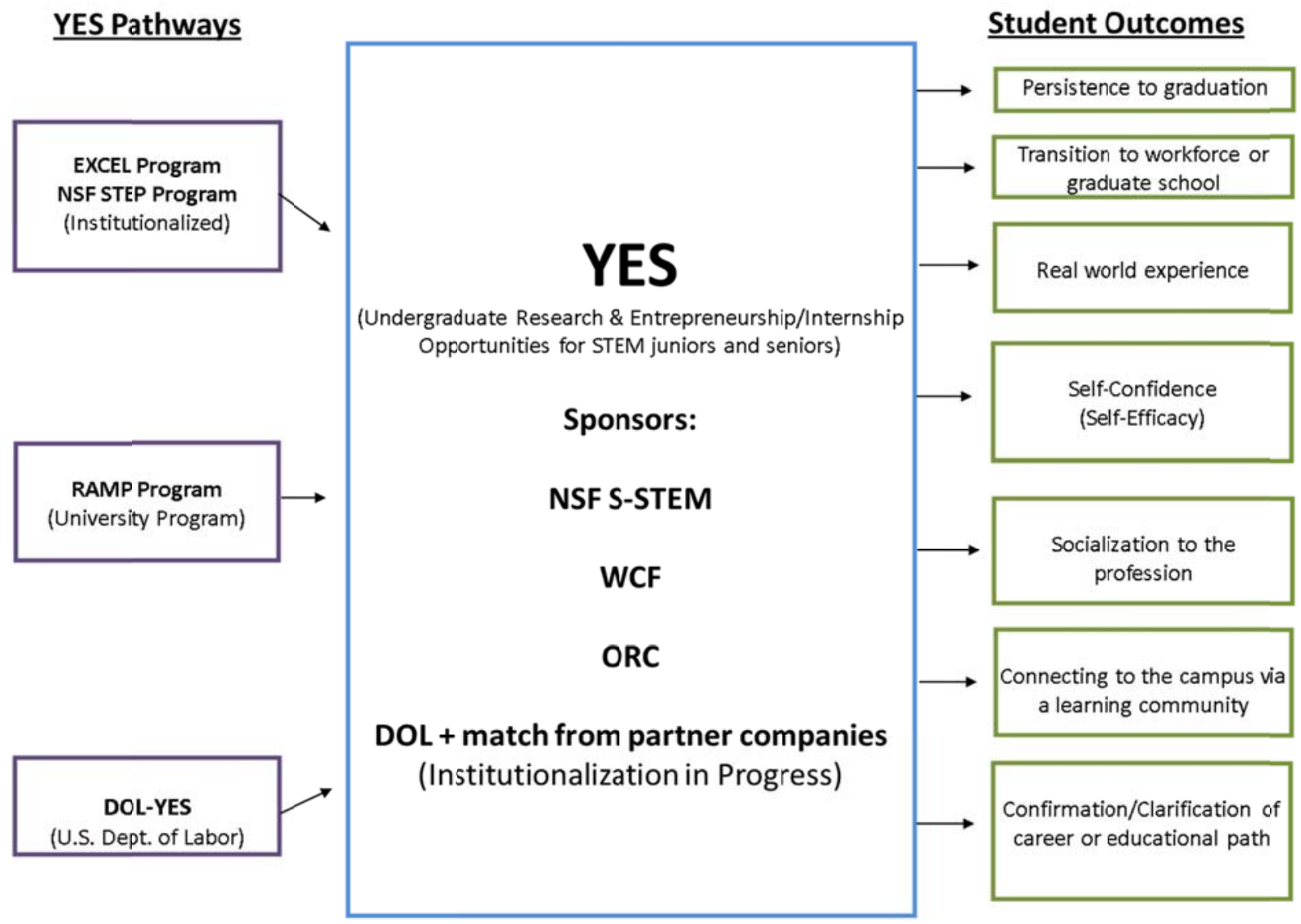

Figure 1. The YES program recruitment pathways, sponsors, and student outcomes.

Graduation Rates. The cumulative graduation rate of YES students with a STEM degree (as of the beginning of Fall 2012) was 57\% (28/49); 41\% (20/49) were still enrolled in a STEM or STEM-related major; and 2\% (1/49) had dropped out of school. Table 1 shows demographic information for completers (defined as YES students who maintained eligibility to participate in the YES program and remained active in the program from choice) and non-completers (defined as YES students who maintained eligibility to participate in the YES program but did not continue from choice or those who no longer met program requirements and were not eligible to continue participation in the program). Forty-six percent of completers were under-represented minorities (57\% for non-completers); 50\% were women (33\% for non-completers); and 36\% were first generation college students (67\% for non-completers). Thirty-six percent of 
completers had entered the YES program as juniors and 64\% as seniors (for non-completers, $57 \%$ had entered as juniors, $43 \%$ as seniors). Sixty-four percent of completers were engineering and computer science majors (52\% for non-completers). These demographic statistics (Table 1) suggest that the structure of the YES program benefits female students in particular among the completers (50\%) compared with non-completers (33\%). A somewhat larger percentage of engineering and computer science majors were also represented among the completers (64\%) compared with non-completers (55\%). These statistics also show that we need to do a better job of working with first-generation students (completers 36\%, non-completers 67\%).

Table 1. Demographics Statistics for Completers and Non-Completers in YES

\begin{tabular}{lcc}
\hline Demographics Statistics & Completer n $=22$ & Non-Completer n =21 \\
Under-represented minorities & $46 \%$ & $57 \%$ \\
Women & $50 \%$ & $33 \%$ \\
First generation to pursue a Bachelor’s degree & $36 \%$ & $67 \%$ \\
Classification Upon Entry into YES & & \\
Junior classification & $36 \%$ & $57 \%$ \\
Senior classification & $64 \%$ & $43 \%$ \\
Major Upon Entry into YES & & $52 \%$ \\
Engineering and computer science & $64 \%$ & $48 \%$ \\
Other STEM majors & $36 \%$ & \\
\hline
\end{tabular}

Time-to-Degree. Table 2 provides persistence to graduation statistics for completers and noncompleters. The graduation rate for completers was 100\% (22/22); for non-completers, it was 29\% (6/21). The mean entry cumulative Grade Point Average (GPA) into the YES program and mean cumulative GPA upon graduation were relatively stable for both completers and noncompleters, suggesting that participation in the internship or undergraduate research experience did not necessarily result in higher overall GPAs. For completers $(n=22)$, the mean entry cumulative Grade Point Average (GPA) into the YES program was 3.49 (std = .27), and the mean graduating cumulative GPA was $3.44(\mathrm{std}=.28)$. For non-completers $(\mathrm{n}=6)$, the mean entry cumulative GPA into the YES program was 3.29 ( $\mathrm{std}=.34$ ) and the mean graduating cumulative GPA was 3.28 ( std = .29). This finding is consistent with a study by Schuurman, Pangborn, and McClintic ${ }^{14}$ of graduating engineering seniors at Pennsylvania State University. They found that when factoring in pre-work academic performance, work experience resulted in marginal increases in cumulative GPA upon graduation but more work experience resulted in higher starting salaries and the likelihood of receiving a job offer prior to graduation. However, the higher cumulative GPA for the completer group (and anecdotal information from the YES Academic Adviser) suggests that students with higher GPAs may be better at managing the demands of school, extra- and co-curricular activities, family, and other responsibilities.

The data also suggest that completers graduated at a faster rate than non-completers (Table 2), but the sample size for non-completers ( $\mathrm{n}=6$ graduated) is very small. Time-to-degree was 
calculated by taking the difference between the actual number of semesters to graduation and the intent-to-graduate semester listed on the student's application into the YES program, making the assumption that action follows intent. For completers, 50\% graduated on time (20\% for noncompleters), $27 \%$ graduate sooner than expected ( $0 \%$ for non-completers), and $23 \%$ longer than expected (80\% for non-completers). For completers, the average number of semesters from entry into the YES program until graduation was 4.64 semesters ( $s t d=1.53, \mathrm{n}=22$ ); for noncompleters, it was 5.83 ( $\mathrm{std}=1.47, \mathrm{n}=6$ ) semesters. Another limitation to interpreting this data trend, in addition to the small sample size of graduated non-completers, is that seniors were overrepresented among the completers (64\%) with non-completers (43\%); see Table 1.

\section{Table 2. Graduation Statistics for Completers and Non-Completers in the YES Program}

\begin{tabular}{|c|c|c|}
\hline Graduation & Completer $\mathrm{n}=22$ & Non-Completer $\mathrm{n}=6$ \\
\hline Graduation rate* & $100 \%$ & $29 \%$ \\
\hline Mean entry cumulative GPA & 3.49, std $=.27$ & 3.29, std $=.34$ \\
\hline Mean graduating cumulative GPA & 3.44, std $=.28$ & 3.28, std $=.29$ \\
\hline $\begin{array}{l}\text { Mean number of semesters from entry until } \\
\text { graduation }\end{array}$ & 4.64, std $=1.53$ & 5.83, std $=1.47$ \\
\hline $\begin{array}{l}\text { Semesters took longer to graduate than } \\
\text { indicated on application, \%, mean, std }\end{array}$ & $23 \%, 1.5$, std $=.84$ & $80 \%, 2.5$, std $=.58$ \\
\hline $\begin{array}{l}\text { Semesters graduated sooner than indicated on } \\
\text { application, \%, mean, std }\end{array}$ & $27 \%,-1.83$, std $=.75$ & $0 \%$ \\
\hline Graduated on-time as indicated on application & $50 \%$ & $20 \%$ \\
\hline
\end{tabular}

Progress to Graduation. A multiple regression test was performed using SPSS 10.0.7 statistical software to determine if the status of being a completer or non-completer ("Completer" variable) and the time spent in the YES program (“Time Spent in YES” variable) were reliable predictors of the outcome variable, "Progress to Graduation." Although the model ultimately proved to be unreliable (larger sample sizes are needed to re-test the model), it is described here as a first attempt toward a potentially tenable model that could be applied to internship and undergraduate research programs to capture a dimension of their impact on progress to graduation. We were also unable to find a model in the review of literature where progress to graduation as an outcome was used as we defined it in our study. Another limitation of the study is self-selection bias among YES students who choose to continue on in the program compared with those who choose not to, or differences that may exist for those who no longer qualify to remain in the program.

The data in Table 2 above suggested that completers graduated at a faster rate than noncompleters. Forty-two cases (student records that had data for all three variables) were used in the test. The average time that completers were active in the YES program was about double that 
of non-completers. Completers spent an average of 4.00 semesters ( $\operatorname{std}=1.45, \mathrm{n}=21$ ) in the YES program; for non-completers, the average was 1.95 semesters ( $\operatorname{std}=.67, \mathrm{n}=21$ ). The hypothesis was that the more time a student spent in the YES program, the better the time-todegree rate. "Progress to Graduation" was calculated for the students in both groups (completer and non-completer) who had graduated $(\mathrm{n}=28-1=27$, since one student did not indicate the intent-to-graduate semester on the application) by taking the difference between the intent-tograduate semester and the graduation semester. A minus number indicated that the student had graduated earlier than expected, e.g. intent-to-graduate semester Spring 2011, actual graduation semester Fall 2010, would result in a value of -1 . Zero indicated that the student had graduated on time as expected, e.g., intent-to-graduate semester Spring 2011, actual graduation semester Spring 2011. A positive number indicated that the student had graduated later than expected, e.g., intent-to-graduate semester Spring 2011, graduated semester Summer 2011, would result in a value of 1 . Similarly, "Progress to Graduation” was calculated for students who were still enrolled ( $n=15$ ) but who had already exceeded their intent-to-graduate semester as of Fall 2012. A positive number indicated that the student had exceeded their intent-to-graduate semester, e.g., intent-to-graduate semester Spring 2011, as of Fall 2012 semester, would result in a value of 5.

A rule-of-thumb of 15 cases per predictor ${ }^{32}$ was used to determine if the sample size was large enough to run the test (at least $15 \times 2=30$ cases). Since there were 42 cases, we proceeded with the test. The correlation table showed a significant correlation between the predictors, “Completer" and “Time in YES," $\mathrm{R}=.637, \mathrm{p}<.001$, indicating some multicollinearity, but not a substantial correlation $(\mathrm{R}>.9)$.

The model accounted for $14.5 \%$ of variance in the outcome which was statistically significant $\left(\mathrm{R}^{2}=.145 ; \mathrm{F}(2,39)=3.32, \mathrm{p}<.05\right.$; see Table 3$)$, indicating that at this stage of interpretation, the model is significantly better at predicting the outcome than the mean model. In terms of how well the model generalizes, the adjusted $\mathrm{R}^{2}$ value should be the same or close to $\mathrm{R}^{2}$. Our model resulted in a shrinkage of $4.3 \%\left(\mathrm{R}^{2}\right.$ - adjusted $\left.\mathrm{R}^{2}=.145-.102=.043=4.3 \%\right)$, indicating that if the model were derived from the population instead of a sample, it would account for $4.3 \%$ less variance in the outcome ${ }^{32}$. SPSS, however, uses Wherry's equation to derive the adjusted $\mathrm{R}^{2}$. Wherry's has been criticized because it does not show the likely value of $\mathrm{R}^{2}$ if different samples were used from the same population ${ }^{32}$. Stein's equation, however, shows how well the model cross-validates (Equation1) ${ }^{32}$. For our model, Stein's adjusted $\mathrm{R}^{2}$ was 0.9 (where $n=42$, the number of cases; $k=2$, the number of predictors), which would account for $5.5 \%$ less variance in the outcome $\left(\mathrm{R}^{2}\right.$ - adjusted $\left.\mathrm{R}^{2}=.145-.09=.055=5.5 \%\right)$, suggesting that there may be some problems with cross-validity of the model. Our model passed the Durbin-Watson test which checked for correlation in the adjacent residuals (residuals should be uncorrelated to meet the assumption of independent errors). The Durbin-Watson statistic in our model was 1.67 (values $<1$ or $>3$ are cause for alarm; the closer the value to 2 , the assumption is that the adjacent residuals for any two observations are uncorrelated $)^{32}$. 
Stein's equation Adjusted $\mathrm{R}^{2}=1-\left[\left(\frac{n-1}{n-k-1}\right)\left(\frac{n-2}{n-k-2}\right)\left(\frac{n+1}{n}\right)\right]\left(1-R^{2}\right)$

The t-test measures if the $B$-value of each predictor contributes significantly to the model while controlling for the effects of all other predictors ${ }^{32}$. In our model (Table 3), "Completer" is statistically significant $\mathrm{t}(39)=-2.56 \mathrm{p}<.05$. However, “Time in YES” is not statistically significant, $\mathrm{t}(39)=1.83, \mathrm{p}>.05$, and the confidence interval for the $B$-value crosses zero, indicating that in some samples this predictor would have a positive relationship with the outcome and in other samples, a negative relationship with the outcome. The test for multicollinearity of the data revealed a possible issue, not with the Variance Inflation Factor (VIF) or Tolerance (Table 3), but with the variance proportions of the smallest eigenvalue (Table 4). The VIF for predictors in our model is 1.68 ; values $>10$ indicate a problem ${ }^{33,34}$, and the average VIF (1.68 for our model) is not substantially greater than $1^{34}$. The Tolerance value for our model is .59; values $<.1$ indicate a serious problem and $<.2$ a potential problem ${ }^{34}$. However, in examining the variance proportions of the predictors on the smallest eigenvalue (Table 4), “Completer" shows a 37\% variance and “Time in YES” 98\% variance, indicating a collinearity problem and that the variables of the regression coefficient are dependent.

Therefore, the model is unreliable and more data need to be collected to see whether multicollinearity can be lessened. (We are recruiting an additional 60 students into the YES program over the next four years and will re-test the model.) We used a rule-of-thumb of 15 cases per predictor ${ }^{32}$ but stricter guidelines for acceptable sample sizes to achieve statistical power indicate that larger sample sizes are needed. Green ${ }^{35}$ recommends the minimum acceptable sample size to test the overall fit of model is $50+8 k$ where $k=$ number of predictors (for our model, we would need $50+8[2]=66$ cases minimum), and to test individual predictors $104+k$ (for our model, we would need $104+2=106$ cases minimum). Miles and Shelvin ${ }^{36}$ recommend that sample sizes needed to achieve Cohen's ${ }^{37}$ statistical power of .8 are: 1) a large effect requires a sample size of 80 with up to 20 predictors; 2) a medium effect requires a sample size of 200 with up to 20 predictors, but a sample of 100 cases is fine with 6 or less predictors (however, always have a sample size above 60); and 3) a small effect requires a sample size of 600 with 6 or less predictors.

Table 3. Multiple Regression Summary Table: “Completer” and “Time in YES” as Predictors of "Progress to Graduation"

\begin{tabular}{|c|c|c|c|c|c|c|c|c|c|}
\hline \multirow{2}{*}{ Model } & \multicolumn{2}{|c|}{$\begin{array}{l}\text { Unstandardized } \\
\text { Coefficients }\end{array}$} & \multirow{2}{*}{$\begin{array}{c}\begin{array}{l}\text { Standardized } \\
\text { Coefficient }\end{array} \\
\beta\end{array}$} & \multirow{2}{*}{$t$} & \multirow{2}{*}{ Sig. } & \multicolumn{2}{|c|}{$95 \%$ CI for $B$} & \multicolumn{2}{|c|}{$\begin{array}{c}\text { Collinearity } \\
\text { Statistics }\end{array}$} \\
\hline & B & $S E$ & & & & $L B$ & UB & Tolerance & VIF \\
\hline Constant & -.05 & .86 & & -.05 & .96 & -1.79 & 1.70 & & \\
\hline Completer & -2.53 & .99 & $-.49 *$ & -2.56 & .014 & -4.52 & -.53 & .59 & 1.68 \\
\hline $\begin{array}{l}\text { Time in } \\
\text { YES }\end{array}$ & .60 & .33 & .35 & 1.83 & .074 & -.062 & 1.27 & .59 & 1.68 \\
\hline
\end{tabular}

$\mathrm{R}=.381 ; \mathrm{R}^{2}=.145$; Stein's adjusted $\mathrm{R}^{2}=.09 ; \mathrm{F}(2,39)=3.32, \mathrm{p}<.05 .{ }^{*} \mathrm{p}<.05$. CI= Confidence Interval. 
Table 4. Collinearity Diagnostics: Evidence of a Collinearity Problem on Dimension 3

\begin{tabular}{cccccc}
\hline \multirow{2}{*}{ Dimension } & \multirow{2}{*}{ Eigenvalue } & \multirow{2}{*}{ Condition Index } & \multicolumn{3}{c}{ Variance Proportions } \\
\cline { 4 - 6 } & 2.66 & 1.00 & Constant & Completer & Time in YES \\
\hline 1 & .26 & 3.18 & .02 & .03 & .02 \\
2 & .07 & 5.98 & .30 & .59 & .00 \\
3 & & & .68 & .37 & .98 \\
\hline
\end{tabular}

Transition to Workforce or Graduate School. Table 5 shows the transition rate of graduated YES students into the workforce or graduate school. The transition rate of graduated YES students (completers and non-completers) into graduate school was 64\% (18/28), the workforce was 29\% (8/28), and 7\% (2/28) unknown (the two "unknowns" are non-completers who have not responded to follow-up emails). All completers who graduated have continued on to graduate school or entered the workforce in a STEM-related field $(n=22 / 22)$ compared with $67 \%$ of noncompleters who have graduated $(n=4 / 6)$. The final choice of a student's career path upon graduation follows a complex, decision-making pathway. Thirty-six percent (10/28) of graduates pursued the YES Research Path and chose to continue on to graduate school and 7\% (2/28) to enter the workforce. Seven percent (2/28) of graduates pursued the YES Entrepreneurship/ Internship Path and chose to continue on to graduate school and 7\% (2/28) to enter the workforce. Twenty-one percent (6/28) who had participated in both the YES Research and Entrepreneurship/ Internship Paths or had pursued the YES Research Path but had also participated in a co-op or internship external to the YES program chose to continue on to graduate school and 14\% (4/28) to enter the workforce.

Table 5. Graduated YES Students' Transition into the Workforce or Graduate School

\begin{tabular}{lccc}
\hline YES Pathways & Graduate School & Workforce & Not Reported \\
Graduated YES Students & $64 \%(\mathrm{n}=18)$ & $29 \%(\mathrm{n}=8)$ & $7 \%(\mathrm{n}=2)$ \\
Research Path Students & $36 \%(\mathrm{n}=10)$ & $7 \%(\mathrm{n}=2)$ & $4 \%(\mathrm{n}=1)$ \\
Entrepreneurship/Internship Path Students & $7 \%(\mathrm{n}=2)$ & $7 \%(\mathrm{n}=2)$ & $4 \%(\mathrm{n}=1)$ \\
Research and Internship Experience & $21 \%(\mathrm{n}=6)$ & $14 \%(\mathrm{n}=4)$ & $\mathrm{n} / \mathrm{a}$ \\
\hline
\end{tabular}

Cognitive, Personal, and Professional Development. Betz and Klein Voyten ${ }^{38}$ analyzed data collected from 350 students enrolled in introductory psychology courses at a large Midwestern university and found that students' self-efficacy beliefs predicted career indecision and outcomes expectations predicted exploration intentions. Positive academic performance and learning about different career options can lead to a better career decision. Among the benefits of the YES program reported by students is the program's positive impact on students' self-confidence and confirmation or clarification of career or educational goals. The following are quotations from a sampling of YES student exit surveys describing the benefits they have received from 
participation in the YES program. Completer or non-completer refers to completing or not completing the YES program as defined previously in this paper.

Sample \#1 Outcomes: Real-world experience, self-confidence, socialization to the profession

"I was proud of my paper on... [in the Research Path]. The study I conducted showed a lot of interesting results that I could have researched further to write a really great paper. For the Entrepreneurship Path, I made an iPad application that became a prototype for a grant that my company is applying for now. The application really impressed my boss, so much that he is giving me a contract job after I graduate.” (female, completer, hired upon graduation by the company)

Sample \#2 Outcomes: Real-world experience, confirmation/clarification of education/career path

"[What I learned was] being able to apply the knowledge gained from class to real-world engineering problems at a company related to my field of study. When I began college I did not want to go to graduate school mainly because no one in my family has ever been and it was [an] unfamiliar topic to me. Originally my plan was to get my bachelor's degree, then get a job in industry. [I was] allowed the opportunity by the YES program to do internships at a company related to my field of study [which] made all the difference. It gave me the chance to see what it took to be a design engineer and also made me realize how much I don't know. This is why I chose to continue my studies in grad school." (under-represented minority, completer, continued on to graduate school)

Sample \#3 Outcomes: Real-world experience, self-confidence, confirmation/clarification of education/career path

"I was able to apply knowledge learned in the classroom to a real world experience, the opportunity to go to conferences and the research fair was a great experience because it taught me to express the knowledge I gained to others. If I do continue my studies the most influential factor will be the experience I have had throughout the YES program. I only did a year of [research in] the YES program but did a semester [of research] the year prior to joining YES, but the impact was still large enough to give [me] a[n] open mind about graduate school. I think I will go back to graduate school a year or two after I receive my diploma so I can have a more specific study when I go back to school, one that will apply more to what I want to do for the rest of my life. I am currently doing an internship at...[internship external to the YES program]. This was meant to be a summer job but the opportunity for a continued position opened up for me after the work I did over the summer. This job opportunity is the reason I am not continuing my research because there is no way I can do both and continue my studies." (male, non-completer, was hired upon graduation by the company) 
Sample \#4 Outcome: Real-world experience, self-confidence

"Over the last year I have learned more than I could have imagined from fellow undergrads, graduate students and Dr. ... I have not only learned book knowledge, research strategies, hands on experience, but I have also learned a lot about myself and the career path I now am determined to accomplish. I have set much higher aspirations for myself as a result of the confidence I have gained in the lab.” (female, completer, continued on to graduate school)

Sample \#5 Outcome: Confirmation/clarification of education/career path

"I have learned that research is not for me. Although that may seem like no accomplishment at all, I was able to learn more about myself and I feel that is a great accomplishment." (underrepresented minority, non-completer, still enrolled in STEM major)

Learning community. "Learning community" in the YES program is defined as providing a curricular structure that provides opportunities for deeper understanding of the material being learned and closer interaction with faculty and fellow participants ${ }^{39}$. In focus groups conducted for the past two years, YES students have reported that one of the benefits of the program was forming friendships with other YES students. YES students described that working in the similar environment was beneficial and they learned through interacting with each other; friendships were strengthened when friends had classes together; they liked being able to interact with graduate students in labs; and overall, they had positive relationships with their mentors. An outcome of the focus groups was that they requested additional social opportunities to interact with each other. To strengthen the bonding ties beyond the YES program, we also created a YES Facebook page. YES students are invited to join; however, participation is optional. Figure 2 shows four distinctive friendship maps of 12 YES students who chose to join the YES Facebook page. Each student is represented by a letter of the alphabet and their major.

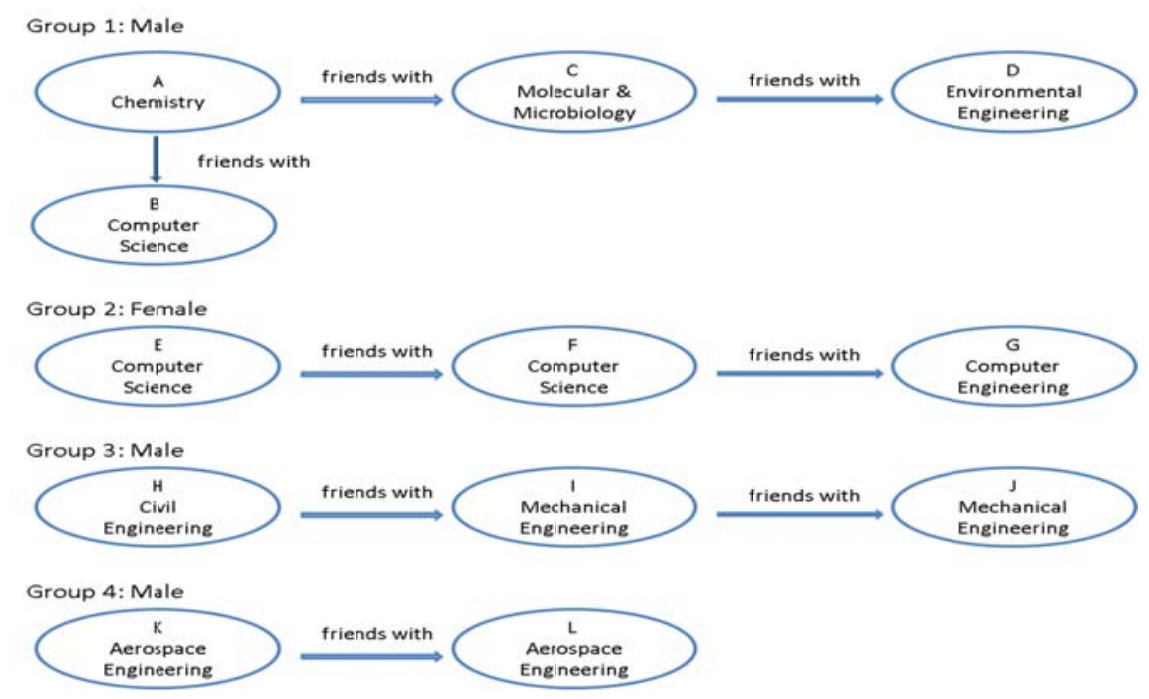

Figure 2. Friendship map of 12 YES students on the YES Facebook page. 


\section{The Partnership Model of the YES Program}

In this section we provide a description of campus programs from which YES students were recruited and of sponsors that have provided financial support to the YES program.

\section{YES Pathways}

The YES program was established in 2008. It was originally conceived as a sister program to the EXCEL program (a NSF-funded STEP program that has since been institutionalized). (STEP stands for Science, Technology, Engineering, and Mathematics Expansion Program.) Whereas EXCEL's focus is recruitment and retention of freshmen students through their sophomore year, YES's focus is persistence to graduation and transition to the workforce or graduate school of juniors and seniors. Students recruited through the EXCEL-YES pathway had the option of participating in the YES Research Path or the YES Entrepreneurship/ Internship Path. Subsequently, a second pathway was added, RAMP-YES. RAMP (Research and Mentoring Program) is a university-sponsored program designed to provide juniors and seniors who are interested in pursuing graduate school with undergraduate research experiences. RAMP applicants who met the YES program requirements were recruited into the YES Research Path, thus allowing the RAMP program to increase the number of students participating in undergraduate research experiences. The newest pathway (effective Fall 2012), DOL-YES, is supported by a grant from the U.S. Department of Labor (DOL) and a company match in the senior year to support interns. The DOL-YES pathway is the beginning of the process to institutionalize the YES program. Figure 1 above shows a visual representation of the YES Pathways and sponsors. A description of the each sponsor follows.

\section{National Science Foundation (NSF) S-STEM Program}

The NSF Scholarships in Science, Technology, Engineering, and Mathematics (S-STEM) program provides institutions with funds for student scholarships based on demonstrated financial need. The purpose of the S-STEM program is to encourage and enable academically talented students to enter the workforce following completion of an associate, baccalaureate, or graduate STEM degree. The program was established by NSF in accordance with the American Competitiveness and Workforce Improvement Act of 1998 and 2004. The Act reflects the national need to increase substantially the number of American scientists and engineers. The YES program was established in 2008 with funding from the NSF S-STEM program.

\section{Office of Research and Commercialization at UCF}

The UCF Incubation and GrowFL programs are administered through the Office of Research and Commercialization (ORC). This office is a partner of the YES program in the newest pathway, DOL-YES, funded by the U.S. Department of Labor. ORC has also provided match funds to support the operations of the YES program. Several of the university's incubation companies have provided mentorship/internship opportunities and a few have hired YES program graduates. 
Since its inception in 1999, UCF's Incubation program has helped more than 300 emerging Central Florida companies create over \$500 million in annual revenue and more than 1,600 new jobs with an average salary of $\$ 59,000$. Much of the regional job growth potential is housed in these STEM incubation-stage businesses, as more than $90 \%$ of resident companies employ ten employees or less and an additional 8\% employ 10-100 employees ${ }^{40}$. In 2004, the Incubation program was recognized by the National Business Incubation Association (NBIA) as "Incubator of the Year.” Other partnership companies for the new pathway, DOL-YES, are also being recruited from industry contacts in the GrowFL program. Economic gardening is a philosophy that embraces strategies to grow existing businesses in a community, region or state. It was pioneered by Chris Gibbons in 1989 in the city of Littleton, Colo., a community that has seen a $71 \%$ increase in employment ${ }^{41,42}$. It was initially introduced as a pilot program to address the sudden decline of economic conditions following the relocation of the largest employer in the city at that time, but since then it has emerged as a prototype for a rapidly expanding movement to generate truly sustainable economic growth for communities, regions, and states.

\section{Workforce Central Florida}

Workforce Central Florida (WCF) has been the authority for workforce planning, programs, and the labor market for the region since 1999. WCF offers various workforce recruiting, retention, and training programs and has been instrumental in supporting internships for young adults. In 2010, using more than $\$ 4.1$ million in stimulus funding from the American Reinvestment \& Recovery Act, WCF created the Summer Job Connection, a program that provided work experience for 1,200 young adults ages 16-21 in worksites including non-profit, government, public sector, emerging and green industries ${ }^{43}$. The program provided nearly 293,000 hours of services for 225 local employers. Paychecks totaling nearly \$2.4 million were released to the interns and into the Central Florida economy. WCF has provided the YES program funds to support student research or internship experiences during the Summer semesters

\section{U.S. Department of Labor (DOL)}

The H-1B Technical Skills Training Grant Program is intended to raise the technical skills of American workers so they can obtain or upgrade employment in high-growth industries and occupations. This grant program is designed to provide education, training, and job placement assistance in the occupations and industries for which employers are using $\mathrm{H}-1 \mathrm{~B}$ visas to hire foreign workers, and the related activities necessary to support such training. Over time, these education and training programs will help businesses reduce their use of skilled foreign professionals permitted to work in the US on a temporary basis under the H-1B visa program. To-date, the H1-B Technical Skills Training Grants have served 22, 545 individuals; 20, 139 have begun training activities, and 17,641 have completed training activities ${ }^{44}$. The newest pathway, DOL-YES, was established in Fall 2012 with DOL funds to support 60 student internships over the next 4 years. 


\section{Conclusion}

Gereffi, Wadhwa, Rissing, and Ong ${ }^{5}$ argued that the quality (not quantity) of the engineering graduate has an important role in innovation and entrepreneurship to remain competitive in the global market. This is a position that we agree with as an institution that produces one of the largest numbers of engineering and computer science graduates with bachelor's degrees in the nation (ranking $20^{\text {th }}$ among 348 engineering schools) ${ }^{4}$. Experiential learning programs (internships, and undergraduate research) play an important role in graduating the quality graduates that employers are seeking to be competitive in the global marketplace. India has an aggressive strategy to expand information technology outsourcing markets for an estimated $80 \%$ incremental growth by 2020 from previously untapped sectors ${ }^{45}$. India currently has a $58 \%$ IT services market share of the global outsourcing market which has provided direct employment to about 2.8 million, and indirectly employing 8.9 million people ${ }^{46}$. According to an article published on CNNMoney.com, in 2009 Applied Materials had to fly in 100 interviewers just to screen the job applicants for 260 positions selected from among 26,000 resumes for its new Solar Technology Center in Xi'an, China, with the final applicants reflecting "the best of the best, topof-their-class, English-speaking engineers" ${ }^{\text {"7 }}$.

It is impossible to tailor the undergraduate curriculum to prepare engineering students to work in specific industry sector of each and every potential area employer. The undergraduate curriculum provides a foundation on which the employer can train the engineering graduate in the requirements of their particular industry sector. However, as one of our major industry partners commented, while our college provides them with good college graduates, it takes six months before they can be trained to be profitable (i.e., productive) to the company. A recent survey of employers by The Chronicle of Higher Education and Marketplace echoes this sentiment. The results of the survey indicated that while most employers feel that colleges do a good job, their new college-degree hires lack basic workplace proficiencies in which employers do not want to take the time to train them ${ }^{48}$. The article also reports that Boeing started ranking colleges in 2008 based on the success of their graduates among their employees. The funding model for the YES program is attractive to area industries as it provides a "free look" or a "try before you buy arrangement" 49 as students are supported through grant funds in the first and second years. The DOL-YES Pathway asks companies to commit to a match of funds to support their YES intern in the second year if they are satisfied with the student's performance in the first year. The added advantage is that students will be trained in the particular industry sector by the end of the internship so that they are productive for the company or a similar employer on day one of employment by the end of the internship experience. The key to being able to begin the process of institutionalizing the program has been to leverage existing resources and funding opportunities that have the same goal.

Florida's state universities have received a substantial budget cut over the past four years. Florida's governor has expressed his commitment to STEM education as pivotal to economic growth as it is estimated that 411,000 STEM-related jobs will need to be filled in the state by 
$2018{ }^{50}$. Several states are investigating ways in which to make STEM degrees more attractive as a choice of major. It is very likely that any new available funding in an austere budget climate will be dedicated to STEM education. Florida, California, and Texas legislators are proposing the creation of STEM degrees that cost no more than $\$ 10,000$ in the hope that by making the degree cheaper to study than other majors, it will attract more students to choose majors in the sciences and technical fields ${ }^{51}$. Ohio's governor and Board of Regents recently allocated \$11 million in funding to support co-op and internships as part of their workforce development plan ${ }^{52}$. The development of STEM talent to meet workforce needs is critical to economic prosperity.

The apprenticeship model has existed for hundreds of years, as far back as the Middle Ages in Britain $^{53}$. The educational approach of the YES program (a mentorship/apprenticeship program) has shown positive outcomes and benefits for the students. YES students have reported that cognitive, personal, and professional benefits include real-world experiences, gains in selfconfidence, development of their professional persona, confirmation or clarification of career or educational goals, and a support network of friends and professionals through the YES learning community. The results achieved through the YES program show that the program has attracted a diverse representation of women, under-represented minorities, and first generation students with STEM majors. YES students are categorized into two groups upon exiting the program: completers and non-completers. Completers are defined as YES students who maintained eligibility to participate in the YES program and remained active in the program from choice. Non-completers are defined as YES students who maintained eligibility to participate in the YES program but did not continue from choice or those who no longer met program requirements and were not eligible to continue participation in the program.

There was a higher representation of female students but lower representation of first generation students among the completers compared with non-completers, suggesting that the structure of the YES program benefits female students in particular but that we need to do a better job with first generation students. As of the beginning of Fall 2012, all completers had graduated and continued on to graduate school or entered the workforce compared with $29 \%$ of non-completers who had graduated of which two-thirds had continued on to graduate school or entered the workforce. The trend data also suggested that YES students who completed the program graduated at a faster rate than those who did not complete the program in its entirety. However, the trend data were biased by the small sample size of the number of non-completers who had graduated and over-representation of the number of seniors among the completers. A multiple regression test was performed with a larger sample data set of YES students which included graduated and still enrolled YES students. "Completer" and "Time in YES" were predictor variables of the outcome "Progress to Graduation." "Completer" was a statistically significant predictor of "Progress to Graduation," but "Time to Degree" was not statistically significant. Multicollinearity was also an issue among the variables. Although the model ultimately proved to be unreliable (even larger sample sizes are needed to re-test the model), it was included in the paper as a first attempt toward a potentially tenable model that could be applied to internship and 
undergraduate research programs to capture a dimension of their impact on progress to graduation. We were also unable to find a model in the review of literature where progress to graduation as an outcome was used as we defined it in our study. We are recruiting an additional 60 students into the YES program over the next four years which should provide the sample size needed to re-test the model. Another limitation of the study is self-selection bias among YES students who choose to continue on in the program compared with those who choose not to, or differences that may exist for those who no longer qualify to remain in the program.

Future research should include the impact of undergraduate research and internship experiences using a larger sample size of STEM students to investigate if a reliable model can be found to predict progress toward the degree and if there are differences by the type of experience (research or internship), and by type of major (engineering or sciences), by demographic type (gender and ethnicity), by institution type (public, private, etc.); the mentor's perspective of student gains; long-term effects of the friendships and networking opportunities achieved through the learning community; and an in-depth examination of students' psychological, decision-making process in selecting their career choice leading up to and upon graduation.

\section{Acknowledgments}

Partial support for this work was provided by the National Science Foundation Scholarships in Science, Technology, Engineering, and Mathematics (S-STEM) program under Award No. 0806931. Any opinions, findings, and conclusions and recommendations expressed in this material are those of the authors and do not necessarily reflect the views of the National Science Foundation. Partial support for this work was also provided by the U.S. Department of Labor, Workforce Central Florida and the university's Office of Research and Commercialization. The authors wish to thank graduate students, Cong Li and Caitlyn McKinzie, for assisting with the literature review, data collection and analysis, and the figures for this paper. 


\section{References}

1. James, M., \& Tanden, N. (2012, August 22). U.S. Education must keep up with China's, India's bold programs. U.S. News. \& World Report, Opinion. Retrieved August 24, 2012 from http://www.usnews.com/opinion/articles/2012/08/22/us-education-must-keep-up-with-chinas-indias-boldprograms

2. Pathak, K. (2010). Engineering graduates could become more unemployable. Business Standard Online Newspaper. Retrieved August 24, 2012 from http://www.business-standard.com/india/news/engineeringgraduates-could-become-more-unemployable/396771/

3. Ministry of Education, People's Republic of China. Educational statistics in 2010: Breakdown of (undergraduate) engineering students by subfield of study in regular higher educational. Retrieved August 31, 2012 from http://www.moe.edu.cn/publicfiles/business/htmlfiles/moe/s6208/index.html

4. Yoder, B.L. (2012). 2011 Profiles of engineering \& engineering technology colleges. Washington, D.C.: American Society for Engineering Education.

5. Gereffi, G., Wadhwa, V., Rissing, B., \& Ong, R. (2008, January). Getting the numbers right: International engineering education in the United States, China, and India. Journal of Engineering Education 97(1), 13-25.

6. Committee on Prospering in the Global Economy of the $21^{\text {st }}$ Century. (2010). Rising above the gathering storm, revisited: Rapidly approaching category 5. Washington, D.C.: The National Academies Press.

7. Committee on Prospering in the Global Economy of the 21st Century. (2007). Rising above the gathering storm: Energizing and employing America for a brighter economic future. Washington, D.C.: The National Academies Press.

8. State University System of Florida Interactive University Database. Degrees tables, 2009-10. Retrieved November 8, 2012 from http://www.flbog.edu/resources/iud/

9. United States Census Bureau. State of Florida 2011. Retrieved November 8, 2012 from http://quickfacts.census.gov/qfd/states/12000.html

10. Hispanic Business Magazine. (2012, August 28). 2012 Top engineering schools. Retrieved August 31, 2012 from http://www.hispanicbusiness.com/branded/2012/best_schools_best_companies/2012_top_engineering schools.asp

11. Swail, W. (2004, June 21,). The art of student retention: A handbook for practitioners and administrators. Educational Policy Institute, Texas Higher Education Coordinating Board 20th Annual Recruitment and Retention Conference, Austin TX. Retrieved February 25, 2013 from http://www.studentretention.org/pdf/ART_OF_STUDENT_RETENTION.pdf

12. Richburg-Hayes, L., Brock, T., LeBlanc, A., Paxson, C., Rouse, C. E., \& Barrow, L. (2009, January). Rewarding persistence: Effects of a performance-based scholarship program for low-income parents. Opening Doors program. Retrieved February 25, 2013 from the Manpower Demonstration Research Corporation (MDRC) website: http://www.mdrc.org/publications/507/overview.html

13. Gross, J. P. K., Hossler, D., Ziskin, M. (2007). Institutional aid and student persistence: An analysis of the effects of institutional financial aid at public four-year institutions. Journal of Student Financial Aid 37(1),28

14. Schuurman, M.K., Pangborn, R.N., McClintic, R.D. (2008, April). Assessing the impact of engineering undergraduate work experience: Factoring pre-work academic performance. Journal of Engineering Education 97(2), 207-212.

15. Strauss, L.C., \& Terenzini, P.T. (2007, December). The effects of students in- and out-of-class experiences on their analytical and group skills: A study of engineering education. Research in Higher Education 48(8), 967991.

16. Dansberry, B.E. (2012). Examining outcomes data from an undergraduate internship program. Proceeding. $119^{\text {th }}$ American Society for Engineering Education Annual Conference \& Exposition, June 10-13, 2012, San Antonio, TX.

17. Tinto, V. (1975, Winter). Dropout from higher education: A theoretical synthesis of recent research. Review of Educational Research 45(1), 89-125. 
18. Paul, E. L., \& Brier, S. (2001, Winter). "Friendsickness” in the transition to college: Precollege predictors and college adjustment correlates. Journal of Counseling \& Development 79, 77-89.

19. Bean, J.P. (1980). Dropouts and turnover: The synthesis and test of a causal model of student attrition. Research in Higher Education 12(2), 155-187.

20. Allendoerfer, C. et al. (2012, July). Strategic pathways for success: The influence of outside community on academic engagement. Journal of Engineering Education 101(3), 512-538.

21. Massi, L., Lancey, P., Nair, U., Straney, R., Georgiopoulos, M., \& Young, C. (2012). Engineering and computer science community college transfers and native freshmen students: Relationships among participation in extracurricular and co-curricular activities, connecting to the university campus, and academic success. ASEE/IEEE Frontiers in Education conference, Oct. 3-6, 2012, Seattle, WA. Paper accepted.

22. National Association of Colleges and Employers. (2012). 2012 Student Survey. Retrieved September 7, 2012 from http://www.naceweb.org/s08012012/paid-intern-job-offer/?referal=knowledgecenter\&menuid=109

23. National Association of Colleges and Employers. (2011). 2011 Internship \& Co-Op Survey. Retrieved September 7, 2012 from http://www.naceweb.org/printerFriendly.aspx?printpage=/s08312011/internship_program/?referal=knowledgec enter\&menuid $=109$

24. Massi, L., Georgiopoulos, M., Young, C., Geiger, C., Lancey, P., \& Bhati, D. (2011). Defining an evaluation framework for undergraduate research experiences. Proceeding. 118th American Society for Engineering Education Annual Conference \& Exposition, June 26-29, 2011, Vancouver, B.C., Canada.

25. Russell, S. H., Hancock, M. P., \& McCullough, J. (2007). Benefits of undergraduate research experiences. Science, 316(5824), 548-549.

26. Lopatto, D. (2004, Winter). Survey of undergraduate research experiences (SURE): First findings. Cell Biology Education 3, 270-277.

27. Lopatto, D. (2007). Undergraduate research experiences support science career decisions and active learning. Life Sciences Education, 6(4), 297.

28. Hathaway, R.S., Nagda, B. A., Gregerman, S.R. (2002, September/October). The relationship of undergraduate research participation to graduate and professional education pursuit: An empirical study. Journal of College Student Development 43(5), 614-631.

29. Seymour, E., Hunter, A., Laursen, S.L., \& Deantoni, T. (2004). Establishing the benefits of research experiences for undergraduates in the sciences: First findings from a three-year study. Science Education 88(4), 493-534.

30. Hunter, A, Laursen, S. L., Seymour, E. (2007). Becoming a scientist: The role of undergraduate research in students' cognitive, personal, and professional development. Science Education 91(1), 36-74.

31. Jimenez, M., Palomera, R., \& Toledo, M. (2002). Undergraduate research and co-op education: A winning combination. Proceeding. $32^{\text {nd }}$ ASEE/IEEE Frontiers in Education Conference, November 2-6, 2002, Boston, MA.

32. Field, A. (2005). Discovering statistics using SPSS (2nd ed.). Thousand Oaks, CA: SAGE Publications Inc.

33. Myers, R. (1990). Classical and modern regression with applications (2nd ed.). Boston, MA: Duxbury.

34. Bowerman, B.L. \& O’Connell, R.T. (1990). Linear statistical models: an applied approach (2nd ed.). Belmont, CA: Duxbury.

35. Green, S.B. (1991). How many subjects does it take to do a regression analysis? Multivariate Behavioral Research 26(3), 499-510.

36. Miles, J., \& Shelvin, M. (2001). Applying regression and correlation: a guide for students and researchers. London: Sage Publications Limited

37. Cohen, J. (1988). Statistical power analysis for the behavioral sciences (2nd ed.). Hillsdale, NJ: Erlbaum.

38. Betz, N.E., \& Klein Voyten, K. (1997, December). Efficacy and outcome expectations influence career exploration and decidedness. The Career Development Quarterly 46, 179-189. 
39. Gabelnick, F., MacGregor, J., Mathews, R. \& Smith, B. L. (1990, Spring). Learning communities: Building connections among disciplines, students and faculty. New Directions in Teaching and Learning (41). San Francisco: Jossey Bass.

40. The Edward Lowe Foundation. Retrieved September 10, 2012 from http://youreconomy.org

41. City of Littleton. Economic gardening. Retrieved September 10, 2012 from http://www.littletongov.org/bia/economicgardening/default.asp

42. Growing Local Economies. Economic gardening. Retrieved September 10, 2012 from http://growinglocaleconomies.com/economic gardening

43. Workforce Central Florida. (2010). 2010 Annual report. Retrieved September 10, 2012 from http://www.workforcecentralflorida.com/about-us/annual-reports/2010-annual-report.stml

44. U.S. Department of Labor. H-1B technical skills training grants. Retrieved September 10, 2012 from https://etagrantees.workforce3one.org/ws/etagrantees/pages/resources.aspx?pparams=1001209351771989496

45. National Association of Software and Service Companies (NASSCOM). Hope on the distant horizon. Retrieved August 31, 2012 from http://www.nasscom.org/Hope-on-the-distant-horizon-56386

46. National Association of Software and Service Companies (NASSCOM). Indian IT-BPO industry. Retrieved August 31, 2012 from http://www.nasscom.org/indian-itbpo-industry

47. Colvin, G. (2010, July 29). Desperately seeking math and science majors. CNNMoney. Retrieved September 13, 2012 from http://money.cnn.com/2010/07/29/news/international/china_engineering_grads.fortune/index.htm\#

48. Fisher, K. (2013, March 4). A college degree sorts job applicants, but employers wish it meant more. The Chronicle of Higher Education. Retrieved March 5, 2013 from http://chronicle.com/article/A-College-DegreeSorts-Job/137625/\#id=overview

49. Coco, M. (2000, Spring). Internships: A try before you buy arrangement. SAM Advanced Management Journal 65(2).

50. Carnevale, A.P., Smith, N., \& Strohl, J. (2010, June). Help wanted: Projections of jobs and education requirements through 2018. State-level analysis, pp. 29-30. Washington, D.C. Georgetown University Center on Education and the Workforce. Retrieved December 10, 2012 from http://www9.georgetown.edu/grad/gppi/hpi/cew/pdfs/florida.pdf

51. Kelderman, E. (2013, January 3). \$10,000 Bachelor's degree is proposed in California legislation. Chronicle of Higher Education. Retrieved January 4, 2013 from http://chronicle.com/article/10000-Bachelors-DegreeIs/136437/

52. Weese, E. (2012, September 13). Ohio makes $\$ 11 \mathrm{M}$ available for internships. Columbus Business First. Retrieved September 14, 2012 from http://www.bizjournals.com/columbus/news/2012/09/13/ohio-makes-11mavailable-for.html

53. National Apprenticeship Service. History of apprenticeships. Retrieved January 4, 2013 from http://www.apprenticeships.org.uk/About-Us/History-of-Apprenticeships.aspx 